Research Article

\title{
Use of Filaria Test Strips (FTS) in Identification of Filaria Endemicity in Non Filaria Endemic Districts of Uttar Pradesh, India
}

\author{
Ramesh Chandra', $^{\text {SM Singh }}{ }^{2}$, Ashish Kumar $^{3}, \underline{\text { S Kamal }}^{4}, \underline{\text { KKMittra }}^{5}, \underline{\text { Nupur Roy }}^{6}$ \\ 1,2,3,4,5 Regional Office of Health \& Family Welfare, Govt. of India, Kendriya Bhawan, $9^{\text {th }}$ Floor, Aliganj, Lucknow, U.P., India. \\ ${ }^{6}$ Dte. of National Vector Borne Disease Control Programme (NVBDCP), 22-Sham Nath Marg, Delhi, India. \\ DOI: https://doi.org/10.24321/0019.5138.202043
}

\section{I $\quad \mathbf{N} \quad \mathbf{F} \quad \mathbf{O}$}

\section{Corresponding Author:}

S Kamal, Regional Office of Health \& Family Welfare, Kendriya Bhawan, 9th Floor, Aliganj, Lucknow, U.P., India

E-mail Id:

shaukatkamal25@yahoo.in

Orcid Id:

https://orcid.org/0000-0002-3358-1572

How to cite this article:

Chandra R, Singh SM, Kumar A, Kamal S, Mittra KK, Roy N. Use of Filaria Test Strips (FTS) in Identification of Filaria Endemicity in Non Filaria Endemic Districts of Uttar Pradesh, India. J Commun Dis 2020; 52(4): 70-76.

Date of Submission: 2020-10-06

Date of Acceptance: 2020-12-09

\section{$\begin{array}{llllllll}\mathbf{A} & \mathbf{B} & \mathbf{S} & \mathbf{T} & \mathbf{R} & \mathbf{A} & \mathbf{C} & \mathbf{T}\end{array}$}

\begin{abstract}
Uttar Pradesh is the largest state of India and is comprised of 75 revenue districts. 51 districts of eastern Uttar Pradesh are endemic for LF and are under Elimination of Lymphatic Filariasis (ELF). In order to ensure elimination of the disease from the people, the Mass Drug Administration (MDA) was observed in these 51 districts since 2004 by ensuring administration of drug DEC alone once in a year according to the age excluding children $>2$ years, pregnant women \& seriously ill persons. Thereafter, $400 \mathrm{mg}$ albendazole to $>2$ years age group was added with DEC since 2008. 24 districts of Western Uttar Pradesh are non endemic for filariasis. The state in coordination with WHO has conducted filaria antigenemia tests in these 24 non filaria endemic districts with the help of Filaria Test Strips (FTS) and the drive is termed as Mini-transmission assessment survey (Mini-TAS). 300 persons were examined with Filaria Test Strip (FTS) from each of the 04 sentinel sites of each district. On the basis of test reports, all 24 non endemic districts reported $>2 \%$ filaria antigenemia and the state claimed to declare the districts as filaria endemic districts/ areas. The possibilities of the claim to establish non filaria endemic districts to filaria endemic districts have been explored \& discussed in detail in this paper. The critical examination of the data does not support to assign any non endemic area to endemic area. On the basis of conducting direct filaria antigenemia tests alone and the term used as mini-transmission assessment survey ('Mini-TAS') will be a misnomer, consequently misleading to the ELF programme in the country.
\end{abstract}

Keywords: Filaria Test Strip, Filaria Antigenemia, Transmission assessment survey, Non-Filaria Endemic, Sentinel Site

\section{Introduction}

Lymphatic filariasis, a vector borne disease transmitted by mosquitoes has been a major public health problem, next to malaria in India and is the second disease responsible for causing highest deformity among human beings. The infection of the disease is transmitted into early age-hood 
but manifestation is experienced in older age after a long time interval. No technique remained available to diagnose the infection in its early time, thereby depriving them for the early treatment. The disease was recorded in India as early as 6 th century B.C. by famous Indian physician-surgeon, Sushruta, in his book "Sushruta Samhita". Madhavakara described the signs and symptoms of the filariasis disease in his treatise "Madhava Nidhan" in 7th century A.D., which hold good even today. ${ }^{1}$

Although not accountable for mortality, yet the disease is responsible for causing social stigma among affected people due to irreversible chronic manifestations viz. swollen limbs, enlarged scrotum \& breast, even chyluria too and economic loss due to confinement on bed for few days rest. National Filaria Control Programme (NFCP) was launched in India in 1955 for control of bancroftian filariasis with objectives of undertaking: (i) Delimitation surveys in known endemic areas, (ii) Large scale control measures in selected areas, and (iii) Training of personnel required to man the programme.

Accordingly, the surveys were undertaken throughout the state and depending upon the high microfilaria prevalence, NFCP units (with one control unit for undertaking anti-larval measures at weekly interval \& one clinic) were established in 29 districts and two more districts (Kanpur and Allahabad) with urban malaria units, which had similar work to filaria control unit were provided with one clinic each. Thus, 31 districts of eastern Uttar Pradesh had NFCP establishment, which have been raised to 51 as a result of division of some parent districts to two or three and are under Elimination of Lymphatic Filariasis (ELF) but 14 districts in western Uttar Pradesh did not qualify for establishing the NFCP set up due to low microfilaria prevalence and absence of congenial environmental conditions like humidity \& temperature required for active transmission of the disease. Thus, these 14 districts, have, now become 24 in number, were considered to be non-endemic for Lymphatic Filariasis. The prevalence of the disease cases and microfilaria among the community was the main criteria for deciding the endemicity of the filaria under the programme. The different chronic manifestations of the disease were clearly visible, but the young ones of the filaria parasite Wuchereria bancrofti called microfilaria are microscopic \& nocturnal in nature due to which they can be seen only in peripheral blood stream during night time, and blood smears can be collected for examination. The person harbouring this parasite may be asymptomatic and microfilaria carriers may become source of infection to other healthy personnel. Hence, to assess a person for infection of filariasis, the sample collection for examining microfilaria is troublesome both for the examinee and sample collector/ examiner.

Now, various tools have been developed as a result of researches and in the sequence of the same, Filaria Test Strips (FTS) have been developed/ manufactured by the Alere "Filariasis Test Strips", which detect the antigenemia of Wuchereria bancrofti even during day time, unlike that of microfilaria which is conducted during night hours, hence, facilitating the surveyor to assess the presence of filaria parasite during day time but not applicable to assess the presence of microfilarimia. Therefore, to assess any contraction of new infection of filariasis among the virgin population, either protected as result of intervention or preventive measures in its early age. This process of assessing the contraction of infection in virgin young children is called the "Transmission Assessment Survey (TAS)" and this test is to be performed among such population thrice at an interval of two years before declaring it free from the active transmission.

The State Programme Officer (SPO), responsible for LF elimination programme instructed all the twenty four (24) non-filaria endemic district authorities to conduct the surveys with the help of Filaria Test Strip (FTS) to assess the LF endemicity and called it as mini-TAS. The main objective of this study was to: (a) validate the use of FTS in Filaria non-Filaria endemic areas without any past anti filarial interventions, (b) establish non-filaria endemic districts to filaria endemic districts and (c) validate the terminology "mini-TAS" used loosely in conducting the present survey. The findings of the study are presented and discussed briefly in present paper.

\section{Materials \& Methods}

The state programme authorities instructed the authorities of 24 non-filaria endemic districts for conducting so called mini-TAS with the help of Filaria Test Strip (FTS) and the target age group recommended for test included older children of age group of 9-14 years. They were asked to enlist entire school list of class 4-8 (age 9-14 years) of the district (Public, Private, Religious etc.). The sampling design in Indian context adopted as Cluster sampling (when total number of schools are more than 40) (Primary schools with grade 1 to 4 should exclude from list but secondary schools with grades 5-10 should be included in the school list. Grades should be selected, where the majority of children are typically 9 years or older. The 30 clusters were selected using population proportional to estimated size, which means that the probability for a school being selected into the survey is proportionate to how large the school is (e.g. Schools with many students are more likely to be selected into the survey than schools with few students). As per directives from the state, initially, all the schools were enlisted and identified for the survey. From each of these 30 schools, 16 students were selected for antigenemia testing (sample size $/ 30$ clusters $=480 / 30=16$ ). 
To achieve 16 numbers, a sampling fraction was calculated for each school as follows: (sample size)/ (school population in target grades). For example- if a school has 128 students in grades $4-8$, then the sampling would be $128 / 16=8$, meaning that 1 out of every 8 students will be selected into the survey from that school (on average this should result in a sample of 16 students). The sampling fraction should be set up in each of the selected school. The FTS were ensured for availability in sufficient number (including 10\% buffer). The Plan for mini-TAS was prepared \& accordingly, it was implemented. A list of uncertain areas /districts was prepared and mini-TAS conducted and endemicity status was determined in all the listed districts/areas. Best practices were adopted and followed in conducting mini-
TAS. The separate and dedicated teams were formed and trained for conducting mini-TAS. The tests were conducted with close collaboration of primary \& secondary school education. Some of villages of district Bulandshahar and Mathura, related to the Filaria antigenemia positive children were surveyed for lymphodema/hydrocele cases and these children were also subjected for Night Blood Survey (NBS) in 2019. The findings obtained so, were analysed statistically and described in the present article.

\section{Result and Discussion}

The filaria antigenemia positivity determined in the survey conducted (so called mini-TAS by the state) is reflected in Table 1.

Table I.Report for Mini TAS 2018 in 24 Non-Endemic Districts in UP

\begin{tabular}{|c|c|c|c|c|c|c|c|c|}
\hline $\begin{array}{l}\text { S. } \\
\text { No. }\end{array}$ & $\begin{array}{l}\text { Name of TAS } \\
\text { districts }\end{array}$ & Tested & $\begin{array}{c}\text { Total } \\
\text { positive }\end{array}$ & Negative & Invalid & Total tests & $\begin{array}{l}\text { Net } \\
\text { tests }\end{array}$ & $\begin{array}{c}\text { Antigenemia } \\
\text { positivity } \\
\text { rate (\%) }\end{array}$ \\
\hline 1 & 2 & 3 & 4 & 5 & 6 & $7(4+5+6)$ & $8(3-6)$ & $9(4 \times 100 / 8)$ \\
\hline 1. & Kashganj & 520 & 33 & 448 & 39 & 520 & 481 & 6.35 \\
\hline 2. & Mainpuri & 554 & 72 & 378 & 104 & 554 & 450 & 16.00 \\
\hline 3. & Firozabad & 515 & 20 & 461 & 34 & 515 & 481 & 3.88 \\
\hline 4. & Bijnore & 510 & 3 & 477 & 30 & 510 & 480 & 0.59 \\
\hline 5. & Jhansi & 569 & 36 & 444 & 89 & 569 & 480 & 6.33 \\
\hline 6. & Lalitpur & 578 & 25 & 446 & 107 & 578 & 471 & 4.33 \\
\hline 7. & Meerut & 580 & 5 & 426 & 149 & 580 & 431 & 0.86 \\
\hline 8. & Ghaziabad & 525 & 10 & 516 & 69 & 595 & 456 & 1.68 \\
\hline 9. & G.B.Nagar & 501 & 5 & 483 & 13 & 501 & 488 & 1.00 \\
\hline 10. & Saharanpur & 539 & 9 & 483 & 47 & 539 & 492 & 1.67 \\
\hline 11. & Muzaffar Nagar & 499 & 4 & 485 & 10 & 499 & 489 & 0.80 \\
\hline 12. & Sambhal & 581 & 18 & 461 & 102 & 581 & 479 & 3.10 \\
\hline 13. & Hapur & 488 & 12 & 476 & 92 & 580 & 396 & 2.07 \\
\hline 14. & Badaun & 539 & 27 & 462 & 50 & 539 & 489 & 5.01 \\
\hline 15. & Bulandsahar & 578 & 5 & 519 & 54 & 578 & 524 & 0.87 \\
\hline 16. & Shamli & 521 & 29 & 442 & 50 & 521 & 471 & 5.57 \\
\hline 17. & Aligarh & 481 & 26 & 282 & 173 & 481 & 308 & 5.41 \\
\hline 18. & Agra & 547 & 11 & 478 & 58 & 547 & 489 & 2.01 \\
\hline 19. & Mathura & 507 & 7 & 479 & 21 & 507 & 486 & 1.38 \\
\hline 20. & Moradabad & 610 & 30 & 462 & 118 & 610 & 492 & 4.92 \\
\hline 21. & Amroha & 553 & 28 & 449 & 76 & 553 & 477 & 5.06 \\
\hline 22. & Baghpat & 533 & 8 & 473 & 52 & 533 & 481 & 1.50 \\
\hline 23. & Etah & 579 & 23 & 531 & 25 & 579 & 554 & 3.97 \\
\hline \multirow[t]{2}{*}{24.} & Hathras & 509 & 82 & 405 & 22 & 509 & 487 & 16.11 \\
\hline & Total & 12916 & 528 & 10966 & 1584 & 13078 & 11332 & 4.04 \\
\hline
\end{tabular}


Table 2.Report of Night Blood Survey (NBS) carried out in antigenemia positive children of filaria non-endemic districts in U.P.

\begin{tabular}{|c|c|c|c|c|c|c|c|c|}
\hline $\begin{array}{l}\text { S. } \\
\text { No. }\end{array}$ & District & Block & Village & $\begin{array}{c}\text { Population } \\
\text { of village }\end{array}$ & $\begin{array}{c}\text { No. } \\
\text { of B/S } \\
\text { Coll./ } \\
\text { Exam. }\end{array}$ & $\begin{array}{l}\text { No. of } \\
\text { B/S +ive } \\
\text { for } m . f .\end{array}$ & $\begin{array}{l}m . f . \\
\text { rate } \\
(\%)\end{array}$ & Remarks \\
\hline 1 & 2 & 3 & 4 & 5 & 6 & 7 & $8(6+7)$ & 9 \\
\hline \multirow{2}{*}{1.} & \multirow[t]{2}{*}{ Mathura } & Sonai & Sarupa & 840 & 3 & 00 & 00 & \multirow{2}{*}{$\begin{array}{c}\text { No history of to \& fro } \\
\text { movement of filaria } \\
\text { endemic area }\end{array}$} \\
\hline & & Govardhan & Rasulpur & 3150 & 4 & 00 & 00 & \\
\hline \multirow[b]{2}{*}{2.} & \multirow[b]{2}{*}{ Bulandshahar } & Jahangirabad & Jahangirabad & 22000 & 2 & 00 & 00 & \multirow{2}{*}{$\begin{array}{l}\text { No history of to \& fro } \\
\text { movement of filaria } \\
\text { endemic area }\end{array}$} \\
\hline & & Malagarh & Dhakauli & 1235 & 3 & 00 & 00 & \\
\hline
\end{tabular}

Table 3.Report of filaria cases (line list) of antigenemia positive children of Non-Endemic Districts in UP

\begin{tabular}{|c|c|c|c|c|c|c|c|c|}
\hline $\begin{array}{l}\text { S. } \\
\text { No. }\end{array}$ & District & Block & Village & $\begin{array}{c}\text { Population } \\
\text { of village }\end{array}$ & $\begin{array}{c}\text { No. of } \\
\text { Iympho } \\
\text { dema } \\
\text { cases }\end{array}$ & $\begin{array}{l}\text { No. of } \\
\text { hydrocele } \\
\text { cases }\end{array}$ & $\begin{array}{l}\text { Total } \\
\text { filaria } \\
\text { cases }\end{array}$ & Remarks \\
\hline 1 & 2 & 3 & 4 & 5 & 6 & 7 & 8 & 9 \\
\hline \multirow[t]{2}{*}{1.} & \multirow[t]{2}{*}{ Mathura } & Sonai & Sarupa & 840 & 00 & 00 & 00 & \multirow{2}{*}{$\begin{array}{l}\text { No history of to \& } \\
\text { fro movement to } \\
\text { fil. Endemic area }\end{array}$} \\
\hline & & Govardhan & Rasulpur & 3150 & 00 & 00 & 00 & \\
\hline \multirow[b]{2}{*}{2.} & \multirow[b]{2}{*}{ Bulandshahar } & Jahangirabad & Jahangirabad & 22000 & 00 & 00 & 00 & \multirow{2}{*}{$\begin{array}{l}\text { No history of to \& } \\
\text { fro movement to } \\
\text { fil. Endemic area }\end{array}$} \\
\hline & & Malagarh & Dhakauli & 1235 & 00 & 00 & 00 & \\
\hline
\end{tabular}

It is evident from Table 1, that district Meerut, Bijnore, Muzaffarnagar, \& Bulandshahar had $<1 \%$ filaria antigenemia positivity and district Ghaziabad, Gautam Budh Nagar, Saharanpur, Baghpat, Mathura had $<2 \%$ filaria antigenemia positivity. Thus, 09 districts bordering Haryana \& Delhi did not had $>2 \%$ filaria antigenemia positivity. Two districts (Agra \& Hapur) had just $2 \%$ filaria antigenemia positivity, On the other hand, 13 districts reflected $>3 \%$ filaria antigenemia positivity (>3 \& <5\%: five districts, Firozabad, Lalitpur, Sambhal, Moradabad \& Etah; (>5 \& <10 \% : six districts, Aligarh, Amroha (Jyotiba Phule Nagar), Badaun, Jhansi, Kasganj \& Shamli; >10\%: two districts, Hathras \& Mainpuri). On the basis of these findings, State Health authorities has directed to conduct Mass Drug Administration (MDA) in those fifteen (15) districts (60\% of the filaria non-endemic districts), where they had $>2 \%$ filaria antigenemia positivity. This exercise was performed without reviewing the existing filaria situation in the districts assuming that "when 51 districts of Uttar Pradesh are endemic for filariasis, the remaining 24 districts must also be endemic for filariasis" (Figure 1-3). The assumption of rationale for the reason is that the changing environmental conditions may support the transmission of the disease. The night blood survey conducted for microfilarimia among filaria antigenemia positive children of some of these districts was conducted, the result obtained (Table 2 ), did not reflect any microfilariamia positivity. It was also recorded on survey that the areas/ villages of some districts of filaria antigenemia positive children did not report any case of lymphodema or hydrocele (Table 3). Thus, there is no visible source of filaria infection and did not had any history of past filaria infection.

As per NVBDCP guidelines on elimination of lymphatic filariasis ELF), any area subjected for any intervention measure should be surveyed for base line data of filaria line list cases (lymphodema, hydroceele, chyluria)..$^{3-5}$ On the basis of filaria line list cases, the night blood survey in 4 sentinel \& 4 random (spot check) sites should be conducted by screening at least 500 blood samples from each site, resulting total screening of at least 4000 persons of different age groups. The representative areas pertaining to each site with $>1 \%$ microfilarimia to be subjected for MDA excluding children $<2$ years age, pregnant women \& seriously ill persons. After ensuring good coverage i.e. consumption of drug by $65 \%$ of the total population or $85 \%$ of the targeted population for consecutive five years and $<1 \%$ microfilarimia the area should be proposed for First transmission Assessment Survey (TAS) after ensuring $<1 \%$ microfilarimia in 10 additional random 
sites in order to ascertain the ongoing transmission of the disease in the area. It is repeated twice at an interval of two years without any intervention measures. The targeted age group for the TAS is 6-7 years or students in standard of Ist \& IInd, presuming that children consuming drug during MDA for five consecutive years must be free from the infection of filaria thereby, reflecting no antigenemia of filaria parasite.

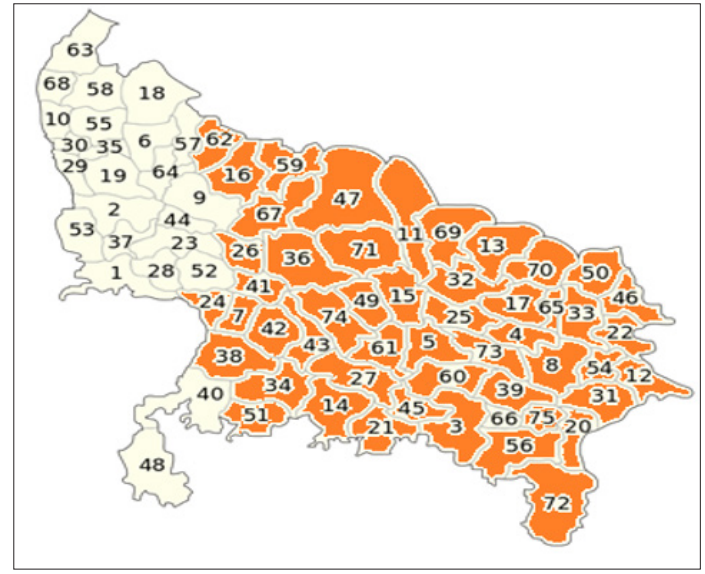

Figure I.Filaria endemic 5 I districts of UP

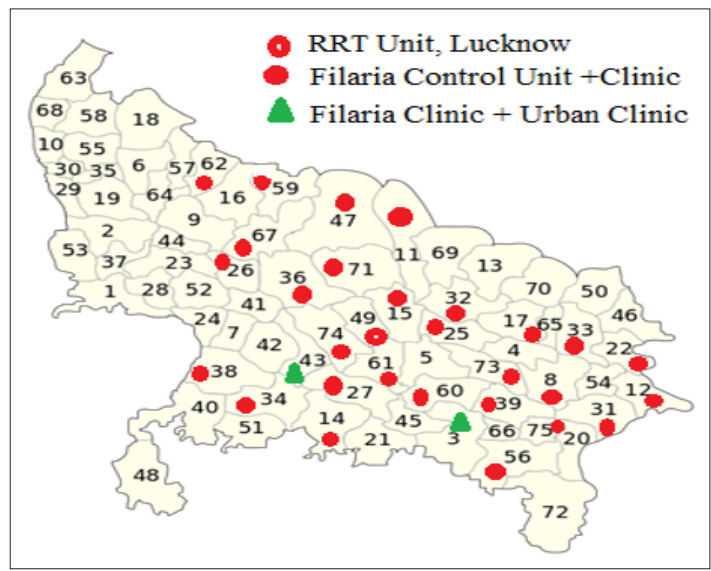

Figure 2.NFCP set up in Uttar Pradesh

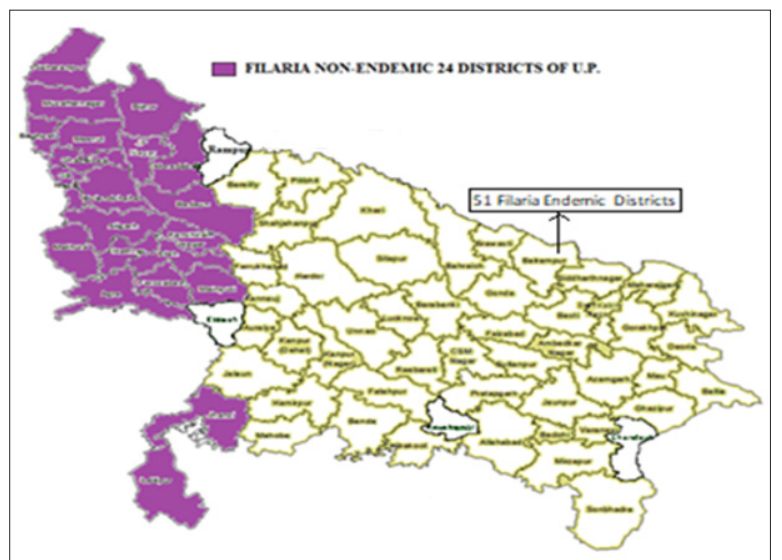

Figure 3.Filaria non-endemic 24 districts of U.P. surveyed for LF with FTS in the school children aged 09-I 4 years (named as mini-TAS)

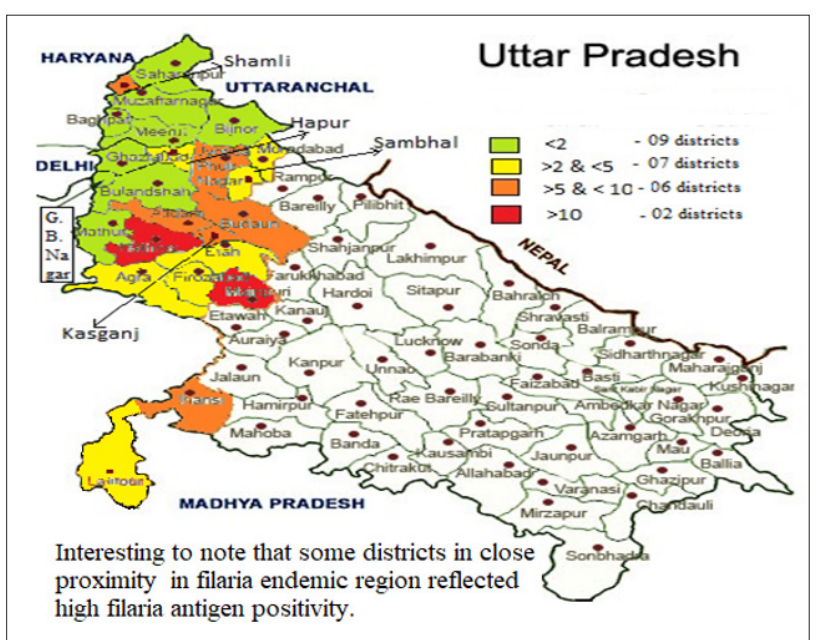

Figure 4.Filaria antigenemia prevalence (\%) in filaria non-endemic 24 districts

The so called mini-TAS was conducted directly in filaria nonendemic 24 districts (Figure 3 ) without preparing any line list survey of filaria cases and night blood survey. Moreover, the age group of children targeted for the survey of antigenemia of filaria parasite was kept 9-14 years, which is quite different from the age group targeted for TAS. The presence of the antigenemia of filaria in the children of 9-14 years age group may have more probabilities to contract infection of filariasis, clearly infers that transmission of filaria has not been stopped in the population and affirm to the contention of non-consumption of the drug during preceding MDA or have visits with halt in more filaria endemic region. The selection of age group is not relevant to rationale of the task undertaken.

The sample size in mini-TAS was fixed to be 480 to one implementation unit (IU) which is very small in comparison to the sample size of 4000-5000 sample screening in night blood survey. Moreover, the age group targeted for survey is 9-14 years (students of 4-8 standard) and may not be representative of whole population as the older age groups have higher filaria antigenemia positivity in comparison to the younger age groups as reflected in the study conducted by the manufacturer of the FTS. In mini-TAS, 9 years was fixed as lower ebb of age group for survey, is not explained clearly and likewise for upper age ebb of 14 years? The state instructions envisage as soon as the threshold level of positive antigenemia test, which is more than two percent of the surveyed population, no further testing is needed and survey can be stopped here and district should plan for the first round of MDA but is it possible to implement this, when the state has not followed the proper track of the survey even after there are no records (historical, hospital, line list of cases) and reports or research findings indicating the presence of transmission.

The instructions of the manufacturer, Alere "Filariasis Test Strip" prospective clinical study, conducted in a Wuchereria 
bancrofti, the performance of the Alere "Filariasis Test Strip" has not been established in non-endemic, low infection level areas and the positive result of FTS does not rule out co-infections with other pathogens, which is clear indicative of the fact that the other nematode pathogens may also counter act instead of $W$. bancrofti. Moreover, age group of the children targeted for testing in the present survey, is more vulnerable for many more worm infestation, and may reflect positivity in FTS. The absence of microfilaria in blood (Table 2) and absence of filaria disease cases (Table 3 ) in the inhabitation area of the FTS positive children, their no history of movement to the filaria endemic areas or movement of infection source to their area are not in support of contracting infection. yet they are reflecting positive results. The filaria antigenemia positivity is exhibited, on loading blood on FTS pad and observing band patterns of test \& control line after 10 minutes of blood loading (Figure 5(a)) and when there is only control line band, the FTS exhibits the filaria antigenemia negativity but at one place (District Hathras), one FTS was reflecting positive test line without loading any blood (Figure 5(c)), what can be the explanation for this condition, is best known to the manufacturer but this can be presumed that the FTS may be sensitive to high temperature and possibly has reflected the band without transfer of blood, when exposed in bright light or high temperature.

Thus, the positive results of FTS obtained from the nonendemic districts/ areas may not be true, in the way the FTS have been used for testing the $W$. bancrofti prevalence, because the results obtained are not in accordance with the NVBDCP procedural guidelines and state's guidelines, yet the survey was conducted on the mutual concurrence of the planner \& implementers (state as well as WHO), which is nothing but the misappropriation of the available resources, needs to be avoided.

The term used as mini-transmission assessment survey ('Mini-TAS') is a misnomer, because the objective of the survey was defined as a new and robust method - miniTAS-is being used in confirmatory mapping of the hitherto uncertain areas. The assessment does not measure the prevalence of microfilaraemia or antigenaemia throughout the Implementation Unit (IU). Rather, it provides a quick and easy estimate of prevalence in areas to be at higher risk than other areas for the purpose of assessing whether the prevalence of infection is high enough in these sites to sustain transmission. The result is used to classify the $\mathrm{IU}$ as a whole as being endemic or non- endemic. All such areas will be subjected to mini-TAS activity. Criteria for selection of uncertain areas: Under accelerated plan miniTAS will be used for re-mapping of areas where there is doubt on endemicity due to reports of cases from these areas. is consequently misleading to the ELF programme in the country. Now the question arise whether the state is intended for mapping of the filaria cases or transmission assessment through mini-TAS, is not clear. If mapping of filaria cases, is to be effected, can be done by simply counting the cases symptomatically \& plotting them in the area map, without the use of FTS, which is a costly tool, both in procurement \& processing. ${ }^{1-2}$

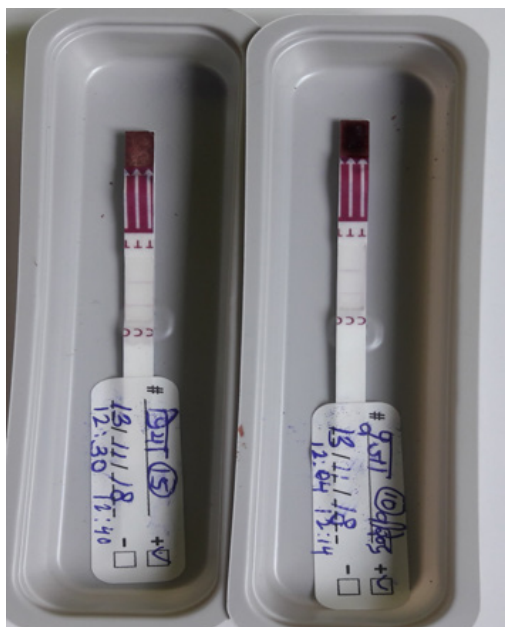

Figure 5(a).Fil. Antigen +ive FTS

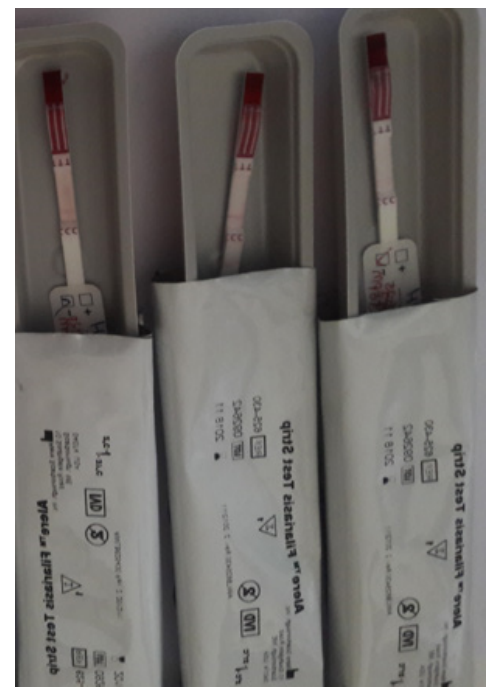

Figure 5(b).Fil. Antigen -ive FTS

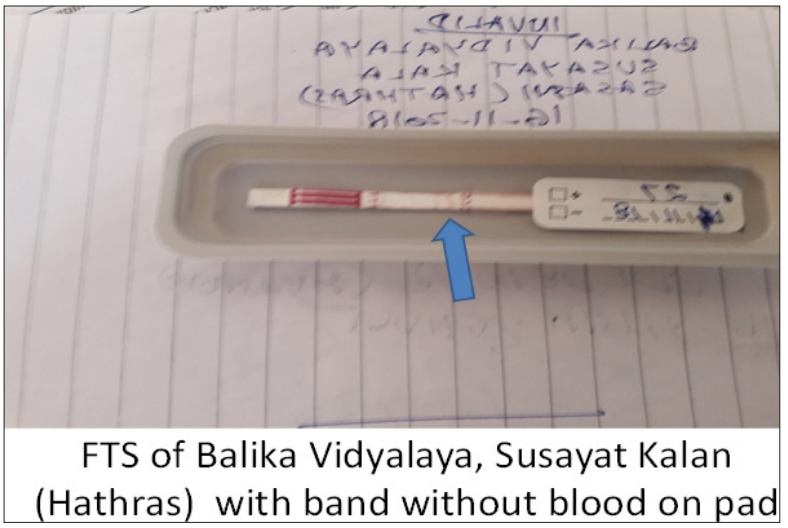

Figure 5(c). FTS exhibiting band without blood loading 


\section{Summary \& Conclusion}

The data obtained as a result of exercise may be used by the state in carrying the detailed surveys among human population for disease cases, microfilarimia both in human beings $\&$ vector mosquitoes and intervention measures undertaken in the districts, which are bordering to the filaria endemic districts, as progression of the disease has been observed in these districts reflecting increase in filaria antigenemia, (Figure 4) possibly as a result of environmental changes or as a result of change in agricultural practices, which may be considered towards positive side, enabling the state to institute appropriate intervention measures to interrupt the progression of the disease towards the nonendemic districts. Hence, NVBDCP guidelines on Elimination of Lymphatic Filariasis (ELF) should be followed strictly for any kind of survey in a systematic way, which are based on exhaustive exercises of the experience of field experts and should avoid the short cuts, including practices of varied nomenclature for pre-existing programme guidelines. The size of sample must be adequate for any survey in proportion to the fixed cut-off benchmark.

\section{Acknowledgement}

The authors are thankful to the State VBD Programme Officer, U.P., Lucknow for his support extended during the field investigations. Thanks are also due to Dr. N. Dhingra, Director, National Vector Borne Disease Control Programme (NVBDCP), Delhi for constant encouragement.

\section{Conflict of Interest: None}

\section{References}

1. Operational Guidelines on Elimination of Lymphatic Filariasis, National Vector Borne Disease Control Programme (NVBDCP), Gol publn. pp.87.

2. National Filaria Control Programme Operational Manual, 1995, National Vector Borne Disease Control Programme (NVBDCP), Gol publn. pp.127.

3. Guidelines on Elimination of Lymphatic Filariasis, India, - Interruption of Disability alleviation through home based management of lymphodema and hospital based hydrocelectomy, 2009, National Vector Borne Disease Control Programme (NVBDCP), Gol publn. pp.108.

4. Elimination of Lymphatic Filariasis India-2013-14, National Guidelines for Transmission Assessment Survey(For district level health Officials), National Vector Borne Disease Control Programme (NVBDCP), Gol publn. pp. 73.

5. Lymphatic Filariasis, TAS Learners Guide, World Health Organization (WHO), publn. pp. 87. 